\title{
Severe knee pain related to statin treatment - not to be confused with osteoarthritis of the knee
}

\author{
Shelly NY Malnick ${ }^{1}$, Peleg Ben Galim², Stephen DH Malnick ${ }^{3}$ \\ 1. Health Science Faculty, Haifa University, Haifa, Israel. 2. Department of Orthopedics, Kaplan Medical Center, Rehovot, \\ Israel. 3. Department of Internal Medicine, Kaplan Medical Center, Rehovot, Israel
}

Correspondence: Stephen DH Malnick. Address: Department of Internal Medicine, Kaplan Medical Center, Rehovot 76100, Israel. Email: stephen@malnick.net

Received: April 12, 2015

DOI : $10.5430 /$ crim.v2n3p1
Accepted: May 5, $2015 \quad$ Online Published: May 11, 2015

URL: http://dx.doi.org/10.5430/crim.v2n3p1

\section{Abstract}

Statins are used extensively for both primary and secondary cardiovascular disease prophylaxis. Although they have a good safety record, side-effects that were not apparent in the registration trials have been noted.

We present two middle-aged men who suffered from severe knee pain and both clinical and radiologic evidence of mild to moderate osteoarthritis. Upon cessation of the statins the complaints resolved. Furthermore the complaints returned on rechallenge. The Naranjo adverse reaction score was calculated at 8 indicating a probable adverse drug reaction.

We believe that it is important for physicians to be aware of this possible cause for knee pain since in many middle-aged patients X-ray or MRI evidence for osteoarthritis may be present but not responsible for the symptoms.

\section{Keywords}

Statins, Myopathy, Osteoarthritis, Knee pain

\section{I ntroduction}

Statin therapy is established treatment of hyperlipidemia, for both primary and secondary prevention of cardiovascular disease $^{[1]}$. The cumulative experience with these agents has shown a good safety profile.

A small proportion of patients (5\%-10\%) report musculoskeletal ache like symptoms (MSK) on statin therapy ${ }^{[2]}$. Several mechanisms for statin-associated MSK symptoms have been suggested including impaired synthesis of coenzyme Q10 (ubiquinone) resulting in mitochondrial dysfunction ${ }^{[3]}$.

Similar MSK symptoms secondary to knee arthritis are commonly experienced by middle-aged patients and may be difficult to distinguish from statin related MSK symptoms. In severe cases, after failure of conservative therapy including analgesia, physiotherapy and intraarticular injections of corticosteroids, surgical treatment is indicated.

Osteoarthritic changes and statin related MSK symptoms may co-exist in this patient age group and therefore it is imperative that physicians be aware of this entity in order to avoid unnecessary knee surgery. We report two cases of 
severe knee pain in patients with osteoarthritic changes on MRI. This pain appears to be related to statin-myopathy with no elevation of muscle enzymes and completely resolved with statin discontinuation.

\section{Case reports}

\subsection{Case 1}

A 50-year-old physician with a history of hypertension and hyperlipidemia underwent coronary angioplasty to a proximal lesion of the left anterior descending artery. His medical treatment consisted of ramipril $5 \mathrm{mg}$ bid, aspirin $100 \mathrm{mg}$ od, amlodipine $5 \mathrm{mg}$ od, metoprolol $200 \mathrm{mg}$ od and atorvastatin $20 \mathrm{mg}$ od. A bare metal stent was inserted. He had 2 years previously had a bare metal inserted into a symptomatic lesion of the circumflex artery. Since his LDL cholesterol level was still $100 \mathrm{mg} / \mathrm{dl}$, after the first angioplasty the dose was increased to $40 \mathrm{mg}$ od. His LDL cholesterol subsequently decreased to $60 \mathrm{mg} / \mathrm{dl}$.

Four years later he started to complain of increasing pain in his left knee. The pain was initially associated with climbing stairs but gradually increased in severity. On examination there was crepitus and tenderness in the interarticular joint space consistent with knee osteoarthritis. On MRI osteoarthritic changes in particular of the lateral aspect of the patella-femoral articulation with marked atrophy of the patellar cartilage and subchondral cysts were noted. There was also atrophy of the lateral anterior femoral condyle.

The patient was advised to stop jogging. Still the pain continued to increase in severity and it became difficult for him to get out of his car. The pain continued to increase and the patella became so sensitive that it was not possible to place the knee on the floor while bending. Laboratory examination revealed normal serum transaminases and creatinine phosphorkinase. The patient made a clinical decision to stop treatment with atorvastatin. Within 3 days there was a substantial improvement, the patient could bend on his knee and he was able to resume normal physical activity including jogging.

\subsection{Case 2}

A 53-year-old man complained of increasing pain in the right knee after climbing stairs. Over the course of the next few months it increased in severity to such an extent that he could not climb stairs at all. In addition he was almost unable to drive due to pain in the knees on pressing the pedals of his car.

His previous medical history was unremarkable except for heavy smoking and hyperlipidemia. He started to take simvastatin $20 \mathrm{mg} 9$ months previously. On physical examination there was a limitation of flexion of the knee and tenderness bilaterally to palpation on the joint line. There was no crepitus and no joint effusion. In addition there was no muscular tenderness present.

Figure 1. Sagittal plane MRI image of the knee (patient\#2) STIR fat suppression sequence showing marked hyperintensity signal in the patello-femoral articulation and a cartilage defect with subchondral cyst formation in the anterior aspect of the femoral condyle secondary to patellafemoral osteoarthritic changes

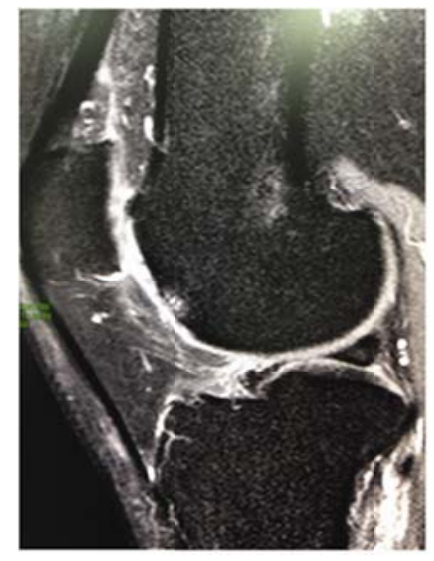

ISSN 2332-7243 E-ISSN 2332-7251 
He underwent an MRI that showed moderate osteoarthritic changes (see Figure 1). Routine laboratory tests were unremarkable, including CPK. He was examined by an orthopedic surgeon who suggested considering knee replacement despite his relatively young age.

We advised a trial of cessation of the statin and within a week his complaints had almost completely resolved and he returned to normal physical activity. Rechallenge with simvastatin was associated with recurrence of his complaints.

In view of the hyperlipidemia he started rosuvastatin $20 \mathrm{mg}$ initially once a week and then slowly increased to three times a week. He reported no further symptoms and his lipid profile was again within the recommended target range.

He has since returned to full activity, with no pain in his knees and no limitation of any daily activity.

\section{Discussion}

We report 2 cases of statin-induced MSK symptoms that were initially misdiagnosed as severe symptomatic osteoarthritis of the knee. Though many patients in this age group are likely to have some degree of osteoarthritic knee changes, it seems that the cause of the pain in these cases was related to statin treatment in view of the rapid response to cessation in both patients and recurrence of the pain after rechallenge in the 2nd case. In the 2nd case with rechallenge being positive the Naranjo adverse reaction score was 8 indicating a probable adverse drug reaction ${ }^{[4]}$.

Statins are very widely used. There is a concern regarding muscle toxicity, although it is rare affecting about $0.1 \%$ of patients ${ }^{[2]}$. The risk for developing muscle injury is different amongst the various statins and is lowest for pravastatin and fluvastatin ${ }^{[5]}$. There is a much higher incidence of musculoskeletal ache with no evidence of myopathy ${ }^{[1]}$.

Myopathic syndromes that are associated with statins range from myalgias to myositis and frank rhabdomyolysis. Although severe myopathic syndromes are usually easy to diagnose, it may be difficult to distinguish between statinrelated myalgia and other cause of muscle pain.

A meta-analysis of 35 randomized controlled trials found no excess risk of myalgias, CPK elevations, rhabdomyolysis or discontinuation of therapy compared to placebo ${ }^{[6]}$.

The incidence of myalgias in clinical trials of statins therapy ranged from $2 \%$ to $11 \%$, similar to the control group ${ }^{[7-10]}$. In addition there was an elevation of CPK in approximately $30 \%$ of both statin-treated and placebo-treated patients ${ }^{[8]}$.

However, clinical experience suggests that muscle side-effects are much more common, including the need to discontinue statins due to side effects. A recent self case report from an Israeli psychiatrist who had received a diagnosis of sciatica, when in fact he had a form of statin myopathy is illuminating ${ }^{[11]}$. There is probably underreporting and in addition, patient selection issues in clinical trials. Although there is likely to be a link between statins and myopathy, it is not recommended to routinely monitor CPK levels ${ }^{[12]}$.

When symptoms develop that may be related to statins, such treatment should be discontinued. In addition if there is an elevation of CPK more than 10 times the upper limit of normal treatment should be discontinued even in the absence of symptoms. Retreatment with pravastatin or fluvastatin is an option for further treatment since these medications have a lower incidence of side effects ${ }^{[5]}$.

Another possibility is the use of "low and slow" rosuvastatin therapy-the administration of low or intermittent dose rosuvastatin which enables the reduction of cholesterol with less side effects ${ }^{[13]}$. In this study coenzyme Q10 (CoQ10) was added to treatment. It is thought that CoQ10 depletion may play a role in statin myopathy and that supplementation may be beneficial $^{[14]}$. 
Since overweight and obesity are risk factors for both cardiovascular disease and osteoarthritis it is likely that many patients receiving statins will have osteoarthritic changes in their knee joints. Furthermore, there is not always a good association between MRI findings of the knees and symptoms function and muscle strength in osteoarthritis ${ }^{[15]}$.

The above cases demonstrate that the musculoskeletal symptoms associated with statins can appear several years after starting the medication, which will delay the suspicion of its link to the patients' complaint. Since many people over the age of 50 have osteoarthritic knee changes on MRI, often in the absence of clinical symptoms, we suggest to consider a trial of statin cessation in some cases. Interestingly a common specific symptom that appeared in both cases presented was severe tenderness of the patella upon contact with the ground in kneeling and may be a suggested clinical clue to consider a trial of cessation of statin therapy.

Statin cessation for a period up to one month is unlikely to have significant adverse effects. It is therefore suggested that physicians be made aware of this important differential diagnosis for anterior knee pain. Furthermore, a short statin cessation trial is to be considered prior to surgical therapy in patients with knee pain who are on statin therapy, especially if there is sensitivity of the patella on contact with the ground.

\section{References}

[1] Taylor F, Huffman MD, Macedo AF, et al. Statins for the primary prevention of cardiovascular disease. Cochrane Database Syst Rev. 2013; 1: CD004816. PMid:23440795 http://dx.doi.org/10.1002/14651858.CD004816.pub5

[2] Grundy SM. Can statins cause chronic low-grade myopathy? Ann Intern Med. 2002; 137: 617-8. PMid:12353951 http://dx.doi.org/10.7326/0003-4819-137-7-200210010-00015

[3] Rundek T, Naini A, Sacco R, et al. Atorvastatin decreases the coenzyme Q10 level in the blood of patients at risk for cardiovascular disease and stroke. Arch Neurol. 2004; 61: 889-92. PMid:15210526 http://dx.doi.org/10.1001/archneur.61.6.889

[4] Naranjo CA, Buso U, Sellers EM, et al. A method for estimating the probability of adverse drug reactions. Clin Pharmacol Ther. 1981; 30: 239-45. PMid:7249508 http://dx.doi.org/10.1038/clpt.1981.154

[5] Graham DJ, Staffa JA, Shatin D, et al. Incidence of hospitalized rhabdomyolysis in patients treated with lipid-lowering drugs. JAMA. 2004; 292: 2585-90. PMid:15572716 http://dx.doi.org/10.1001/jama.292.21.2585

[6] Kashani A, Phillips CO, Foody JM, et al. Risks associated with statin therapy: a systematic overview of randomized clinical trials. Circulation. 2006; 114: 2788-97. PMid:17159064 http://dx.doi.org/10.1161/CIRCULATIONAHA.106.624890

[7] Tobert JA. Efficacy and long-term adverse effect pattern of lovastatin. Am J Cardiol. 1988; 62: 28J-34J. PMid:3055921 http://dx.doi.org/10.1016/0002-9149(88)90004-5

[8] Dujovne CA, Chremos AN, Pool JL, et al. Expanded clinical evaluation of lovastatin (EXCEL) study results: IV. Additional perspectives on the tolerability of lovastatin. Am J Med.1991; 91: 25S-30S. PMid:1831006 http://dx.doi.org/10.1016/0002-9343(91)90053-Z

[9] Boccuzzi SJ, Bocanegra TS, Walker JF, et al. Long-term safety and efficacy profile of simvastatin. Am J Cardiol. 1991; 68: 1127-31. PMid:1951069 http://dx.doi.org/10.1016/0002-9149(91)90182-K

[10] Pedersen TR, Berg K, Cook TJ, et al. Safety and tolerability of cholesterol lowering with simvastatin during 5 years in the Scandinavian Simvastatin Survival Study. Arch Intern Med. 1996; 156: 2085-92. PMid:8862101

http://dx.doi.org/10.1001/archinte.1996.00440170097011

[11] Gropp C. A pain in the tuches. JAMA. 2012; 308: 2467-8. PMid:23287848 http://dx.doi.org/10.1001/jama.2012.68311

[12] Smith CC, Bernstein LI, Davis RB, et al. Screening for statin-related toxicity; the yield of transaminase and creatine kinase measurements in a primary care setting. Arch Intern Med. 2003; 163: 688-92. PMid:12639201 http://dx.doi.org/10.1001/archinte.163.6.688

[13] Vidyarthi M, Jacob P, Chowdhury TA. Oral use of "Low and Slow" Rosuvastatin with Co-Enzyme Q10 in patients with Statin-Induced Myalgia: Retrospective case review. Indian J Endocrinol Metab. 2012; 16(S2): S498-S500. PMid:23565478

[14] Caso G, Kelly P, McNurlan MA, et al. Effect of coenzyme q10 on myopathic symptoms in patients treated with statins. Am J Cardiol. 2007; 99: 1409-12. PMid:17493470 http://dx.doi.org/10.1016/j.amjcard.2006.12.063

[15] Baert IAC, Staes F, Truijen S, et al. Weak associations between structural changes on MRI and symptoms, function and muscle strength in relation to knee osteoarthritis. Knee Surg Sports Traumatol Arthrosoc. 2014; 22: 2013-25. PMid:23377800 http://dx.doi.org/10.1007/s00167-013-2434-y 